\title{
HISTORICIZING “CROSS-CULTURAL”
}

\author{
BENJAMIN PENNY
}

In 2000, a few years into the 10-year history of the ANU's Centre for Cross-Cultural Research, a new field of research for the Centre was announced: "Conceptualising Cross-Cultural Research", which in later years became "Interrogating Concepts of the Cross-Cultural". l The 2007 iteration of the website summarizes it in this way:

$$
\begin{aligned}
& \text { By "cross-cultural research" we } \\
& \text { mean scholarship that is oriented } \\
& \text { towards tracing patterns of trans- } \\
& \text { action and translation between } \\
& \text { cultures. Methodologically, such } \\
& \text { scholarship transcends convention- } \\
& \text { al national and area studies frames } \\
& \text { of reference by recognising the } \\
& \text { increasing porousness of cultural } \\
& \text { boundaries. This program exam- } \\
& \text { ines both the disciplinary and in- } \\
& \text { terdisciplinary ramifications of the } \\
& \text { term "cross-cultural" in Humanit- } \\
& \text { ies research. It does so by explor- } \\
& \text { ing the theoretical links between } \\
& \text { the notion of the "cross cultural" } \\
& \text { as it has emerged in the disciplin- } \\
& \text { ary fields of anthropology, history, } \\
& \text { literary studies and linguistics, and } \\
& \text { contemporary conceptualisations } \\
& \text { of "cultural difference" in the } \\
& \text { transdisciplinary fields of postco- } \\
& \text { lonial, migration and globalisation } \\
& \text { studies. }
\end{aligned}
$$

Although this description locates the particular interest of "cross-cultural research" in recent changes in the state of the world and of academic disciplines, it is clear that "transaction and translation between cultures" has been going on for as long as there have been people, and the "tracing of patterns" in this process is by no means only a recent phenomenon. The essays in this volume are concerned with examining how such patterns were traced before the middle of the twentieth century, when the term "cross-cultural" was coined. They therefore involve studies both of particular encounters between people of different cultures and investigation of the disciplinary categories in which those studies took place.

The literature of encounter between people from different cultural backgrounds is, of course, vast and the essays here only address a few examples of the rich legacy of work left by generations of explorers, traders, missionaries and consular officials, as well as people who thought of themselves as scholars. Some small amount of this work is well known but more of it is much less read than it should be and, in general, deserves rediscovery and reassessment. The people who conducted this research worked within the paradigms of their owns eras: the ways they thought through what they saw and heard may sound unfamiliar, if not simply odd, to a contemporary ear, but such perplexity is all to the good, as it makes us ponder the earlier forms - indeed, often 
the foundations - of the disciplines that currently hold sway.

However, just as the essays in this volume seek to historicize "cross-cultural research", it is also possible, and illuminating, to historicize the word "cross-cultur$\mathrm{al}^{\prime \prime}$ itself, and the major part of this essay will be concerned with the first significant academic project to use the term "crosscultural" in its title. It is important to do this to expose the difference in conceptions between its use today and what it meant at the time of its coining, in order to lay bare the foundations of the field.

The first citation the Oxford English Dictionary gives for "cross-cultural" comes from Malinowski's A Scientific Theory of Culture (1941) in a chapter outlining "Concepts and Methods in Anthropology". Having discussed "evolutionism" and "diffusionism", and mentioning functionalism in passing, Malinowski says:

Thus there is the comparative method, in which the student is primarily interested in gathering extensive cross-cultural documentations, such as we see in Frazer's The Golden Bough, or in Tylor's Primitive Culture, or in the volumes of Westermarck on marriage and morals. In such works the authors are primarily interested in laying bare the essential nature of animistic belief or magical rite, of a phase in human culture or a type of essential organization. Obviously, this whole approach presupposes a really scientific definition of the realities compared. Unless we list, in our exhaustive inventories, really comparable phenomena, and are never duped by surface similarities or fictitious analogies, a great deal of labor may lead to incorrect conclusions. $^{3}$

There are two points that I want to focus on from this passage. First, Malinowski saw Frazer, Tylor and Westermarck - he was probably referring to Westermarck's The History of Human Marriage and The Origin and Development of the Moral Ideas 4 - as using comparison to reveal "the essential nature" of a particular phenomenon, much as nineteenth-century classical philologists sought the underlying IndoEuropean language by comparison of known tongues. In such projects, it is often the origin or source of a specific cultural activity that is the primary goal. This presumes, of course, that there is a shared cultural substratum in humanity; indeed, it may have been argued, that substratum is made up of those essential characteristics that make us human. Secondly, comparison, for Malinowski, meant "cross-cultural documentations" - but it was imperative that those comparisons be made between "really comparable phenomena" specified by a "really scientific definition". He was obviously reacting against some earlier excesses of the comparative method here, but nonetheless we might baulk, some 65 years after Malinowski's death, at the notion that cultural phenomena can be defined with such accuracy and precision, and at the tendency towards circularity in so reducing the set of items we might compare to only such things that we define as being "really comparable" in the first place.

Even so, it is important to recognize that at its appearance in academic writing at least, "cross-cultural" collocated most 
comfortably with the idea that insights into the nature of the human condition could best be drawn through comparing the various forms that particular features of people's lives took in different places and, as we shall see, at different times. The $O E D$ 's definition for "cross-cultural" indicates that it appeared before 1940 and, indeed, in 1937 Yale University launched a major project under the name of "The Cross-Cultural Survey", later incorporated into the Human Relations Area Files. ${ }^{5}$ This survey, headed up by George Peter Murdock (1897-1985), produced both the Outline of Cultural Materials, with its first edition in 1938, and the supplementary Outline of World Cultures, first published in 1954. Both works continue to be revised and published and are now available electronically. Murdock explained the genesis of the project in an article from 1940:

For a number of years, the Institute of Human Relations at Yale University has been conducting a general program of research in the social sciences, with particular reference to the areas common to, and marginal between, the special sciences of sociology, anthropology, psychology, and psychiatry. In 1937, as one of the specific research projects on the anthropological and sociological side of this program, the Cross-Cultural Survey was organized.

A year of previous experience in collaborating with other social scientists in research and discussion had made it clear to the anthropologists associated with the Institute that the rich resources of ethnography, potentially of inestimable value to workers in adja- cent fields, were practically inaccessible to them. Working in the laboratory, the clinic, or the community, the psychologists, sociologists, and others made frequent requests of the cultural anthropologists for comparative data on various aspects of behavior among primitive peoples. Sometimes they wanted perspective, sometimes suggestions, sometimes a check on their own scientific formulations. In trying to assist them, the anthropologists found that they could usually cite a limited number of cases from their own knowledge and give an impressionistic judgment as to the general status of ethnography on the question. For scientists, however, this was often not enough. What guarantee was there that the remembered cases were representative, or the impressions valid? What was needed was access to a dependable and objective sample of the ethnographic evidence. Only rarely was it possible to refer the seeker to an adequate summary of the evidence; in the great majority of instances, he could satisfy his scientific curiosity only by resorting to the vast descriptive literature itself and embarking on a research task of discouraging magnitude. ${ }^{6}$

To overcome this problem, Murdock established the Cross-Cultural Survey, which was designed to be "a representative sample of the cultural materials on the various societies of the world...organized for ready accessibility on any subject". ${ }^{\prime}$ This was an encyclopaedic project; one that sought an Olympian view of all hu- 
manity, a kind of grand ethnographic panopticon with each discrete unit of culture defined and arranged for easy comparison. The foreword to the first edition of the Outline of Cultural Materials states that it was "designed primarily for the organization of the available information on a large and representative sample of known cultures with the object of testing crosscultural generalizations, revealing deficiencies in the descriptive literature, and directing corrective fieldwork" ${ }^{8}$ By the third edition, the goal was significantly more ambitious: the "large and representative sample of known cultures" had become, by 1950, "a statistically representative sample of all known cultures, primitive, historical, and contemporary". ${ }^{9}$ Thus, there were two processes necessary for this project to be fulfilled. First, materials needed to be gathered; secondly, they needed to be classified. Murdock explained the progress in collection in 1940 in this way:

Since the publication of the manual, in 1938, the staff of the Cross-Cultural Survey has been engaged in the actual assembling of materials. To date, the descriptive data on nearly a hundred cultures have been abstracted, classified, and filed. It is hoped ultimately to assemble and organize all the available cultural information on several hundred peoples, who will be adequately distributed with regard to geography and fairly representative of all major types and levels of culture. Although primitive cultures will preponderate numerically, because they reveal the widest range of human behavioral variations, there will be a fair representation of the historical civilizations of the past, of modern folk cultures, and of the communities studied by contemporary sociologists. ${ }^{10}$

The single-minded collection of data was not something that Murdock simply delegated to his staff. An obituary by John W.M. Whiting, one of his former students, in the American Anthropologist recalled that,

When I was a graduate student at Yale in the 1930s, Pete [as he was known to friends and family] would spend nearly every weekday night from 8.00 p.m. to 5.00 a.m. in the Yale library examining every possible source of ethnographic information, identifying the group described and listing all the references. As a consequence he was able to publish a listing of all known cultures of the world The Outlines of World Cultures. This served as an approximation of the universe of known peoples of the world, which was necessary if the aim of the files was to produce a representative sample of this universe. ${ }^{11}$

The completeness of Murdock's files is indicated by his description of the methods of collection:

For each of the cultures analyzed, the entire literature is covered, including manuscript materials when available. In some instances, more than a hundred books and articles have been combed for a single tribe or historical period. All material in foreign languages has 
been translated into English. The information, if of any conceivable cultural relevance, is transcribed in full - in verbatim quotations or exact translations. The object has been to record the data so completely that, save in rare instances, it will be entirely unnecessary for a researcher using the files to consult the original sources. ${ }^{12}$

Classification of the data was according to two broad criteria. The first was geographical: the world was divided into continents or their equivalent, then countries or large portions of countries, then specific groups. Thus, Australia is found under Oceania, with the sub-classifications: "Australia [in general], Historical Australia, Norfolk Island, Prehistoric Australia, Australian Aborigines [in general], Andedja, Arabana, Aranda, Barkindji, Dieri, Kabikabi, Kamilaroi, Karadjeri, Kariera, Kawadji, Kurnai, Murngin, Narrinyeri, Tasmanians, Tiwi, Ualarai, Wikmunkan, Wogait, Worimi, Yiryoront, Yungar". ${ }^{13}$ The second criterion was according to content and is much more complex. In a system reminiscent of Roget's Thesaurus, the entirety of human activity is broken down into 79 sections and 619 subsections. The editors of Outline of Cultural Materials write:

The reader must expect to find classified under the same heading such superficially divergent phenomena as the Indian medicine man and the modern psychoanalyst under Category 756 (Psychotherapists), and the primitive quarrying of flint and the contemporary activities of the Anaconda Copper Company under Category 316 (Mining and Quarrying). Sim- ilarly, there can be no special category like "Christianity," pertaining to only a limited number of cultures, but only general categories like 779 (Theological Systems). ${ }^{14}$

The editors remark that, "any element of culture may have as many as seven major facets any one of which may be used as the primary basis of classification", and proceed to list these facets as being:

1. a "patterned activity" (travel, conversation, crime),

2. only occurring under certain circumstances (rest days and holidays, disasters, menstruation),

3. being associated with a particular subject (division of labour by sex, sibs, priesthood),

4. being commonly directed towards some object (poultry raising, kin relationships, child care),

5. being accomplished by some external means (telephone and telegraph, weapons, mutual aid, agency),

6. being normally performed with a purpose or goal (mnemonic device, sorcery, techniques of inculcation),

7. having a concrete result (shipbuilding, sanctions). ${ }^{15}$

Systems of classification are, of course, challenging to develop but this one does seem both arbitrary and, in the character of those examples thrust together in parentheses, to approach self-parody. ${ }^{16}$ However, even if we discount the problems associated with developing a taxonomy, the subsequent process of classification of any given cultural phenomenon is itself often complex, difficult and as arbitrary as the classificatory categories themselves. $^{17}$ 
However, for the present purposes the details of the classification scheme that Murdock and his colleagues developed are less important than the fact that he did attempt to encompass "the universe of known peoples of the world" and to produce "a representative sample" of them for the purposes of making comparisons. This striving towards a rigorously defined taxonomy of the entirety of human experience was by no means a new goal. Murdock and his colleagues were clear methodological descendents of Edward Tylor, whose "On a Method of Investigating the Development of Institutions; Applied to Laws of Marriage and Descent" provided the model for this variety of research. As George Stocking remarked, in relation to Herbert Spencer's Descriptive Sociology, "Spencer may thus be regarded as the ultimate source of the later Human Relations Area Files; Tylor, of the systematic comparative cross-cultural study of the data they contain." 18 The purpose of comparison underlying the Cross-Cultural Survey was to find systematic correlations between cultural variables, as Tylor had done. Thus, to take one example, for Guy E. Swanson to answer the question "From what experiences do the ideas of the supernatural and its myriad forms arise?", he analyzed data from a "randomly" selected set of 50 societies from Murdock's list, correlating various aspects of social organization with particular varieties of religious belief: monotheism, polytheism, ancestral spirit belief, reincarnation, the immanence of the soul, witchcraft and the interaction of the supernatural and morality. ${ }^{19}$ His conclusions - in the case of monotheism - are indicative of the style of the whole:
1. Monotheism is positively related to the presence of a hierarchy of three or more sovereign groups in a society.

2. There is no relationship between the number of sovereign groups in such a hierarchy, and the likelihood that the monotheistic deity will be seen as active in earthly affairs including the support of human moral relationships. High gods do tend to be active in societies having two or more sovereign communal groups.

3. A variety of other indices of social complexity are not related to the presence of monotheistic beliefs in a society.

4. The data seem to run counter to the expectation of certain anthropologists that a highly developed monotheism would be likely to appear in the simplest and most isolated societies. ${ }^{20}$

During the late 1930s and 1940s others used "cross-cultural" in this same sense, notably Margaret Mead, ${ }^{21}$ and after the Second World War its use spread widely in Anthropology, Psychology, Education and related fields. At some point in the mid-1950s another sense of "cross-cultural" started to appear. Rather than standing for a type of work that surveyed a range of cultures for examples of a particular phenomenon, it focused on differences between the perceptions two particular peoples held of each other, or the perceptions two particular peoples had of some specific event, or set of circumstances, or object. Thus, for example, the two theses "Military Government and the German Press: an Experiment in Cross-Cultural Institutional Change" and "The Japanese Student's View of America: a Study in Cross-Cultural Perception" were both ac- 
cepted in 1954, the former from Columbia University and the latter from Ohio State University. $^{22}$

This new meaning of "cross-cultural" arguably marks the origin of its use in the context of the encounter between two peoples of different cultures. In the postwar world that saw the start of long-term occupations of defeated countries by their victors - and the continuing presence of their military bases — the increasing presence of foreign students and staff in the universities of the first world, the formation of initiatives such as the Peace Corps and the burgeoning of disciplines like Social Psychology, discussions of how people of different cultures understood each other gained a new relevance. One manifestation of this interest was the development of the field of "cross-cultural training" in the late 1960s and early 1970s, where people about to be posted to another country were sensitized to the different ways their new hosts perceived the world and behaved.

As the decades progressed, there were two fields in which the term "cross-cultural" became preponderant in book titles: one represented the stream concerned with cross-cultural comparison and the other was represented by applied studies of encounter situations. The first was found in medical research where particular diseases or treatments or syndromes were studied, often statistically, in different parts of the world for the purposes of comparison; the second is apparent in the field of "crosscultural communication". By 1997, the year the ANU's Centre for Cross-Cultural Research was founded, the books with "cross-cultural" in their titles in the Library of Congress catalogue still largely comprised works with a strong comparative and statistical bias, notably four volumes of Philip M. Parker's Cross-Cultural Statistical Encyclopedia of the World, or studies of cross-cultural communication - for instance, Cross-Cultural and Interdisciplinary Aspects of Teaching Languages for Professional Communication and CrossCultural Communication and Aging in the United States. ${ }^{23}$ It is interesting, however, that lurking amongst these titles, one book undoubtedly hailing from the humanities appears: Claudio Gorlier and Isabella Maria Zoppi's edited volume Cross-Cultural Voices: Investigations into the Post-Colonial. Despite its title, the essays in this book actually differ little from the traditional study of "Commonwealth Literatures"; indeed, one of its editors disclaims any desire to enter "into the heart of the vital and multi-faceted debate concerning a "post-colonial discourse'", 24 However, the mere juxtaposition of "cross-cultural" and "post-colonial" marks a shift to another variety of "cross-cultural research" — the kind the Centre for Cross-Cultural Research pursued over the decade of its lifetime. One of its five "key programs" was, in fact, "Postcolonialism and Cultural History". ${ }^{25}$ Another, as I noted at the beginning of this essay, was "Interrogating Concepts of the Cross-Cultural", the rubric under which the original series of seminars on "Historicizing Cross-Cultural Research" was given that led to this volume of essays. 


\section{ENDNOTES}

1 I would like to thank Henrika Kuklick for her helpful suggestions in the preparation of this essay.

${ }^{2}$ http://www.anu.edu.au/culture/research/interrogating.php (accessed 7.4.07)

3 Malinowski, B., A Scientific Theory of Culture and Other Essays (Chapel Hill: The University of North Carolina Press, 1944), p.18.

${ }^{4}$ Westermarck, E.A., The History of Human Marriage (London: Macmillan, 1891) and subsequent editions; The Origin and Development of the Moral Ideas (London: Macmillan, 1906-08) and second edition.

5 In 1971, when he was at the University of Pittsburgh, George Murdock and others founded the Society for Cross-Cultural Research, under whose aegis the journal Cross-Cultural Research is published. The website of the society says: "Whereas early members were heavily involved in hologeistic research, often in conjunction with the Human Relations Area Files (HRAF), the methodological perspectives of the membership have broadened over the years to include a wide range of cross-cultural interests and approaches" (http://www.sccr.org/description.html, accessed 13.4.07). Hologeistic — "whole world" research is usefully discussed in Richard W. Thompson and Roy E. Roper, "Methods in Social Anthropology: New Directions and Old Problems", American Behavioral Scientist 23, 6 (July/August, 1980), 905-24, pp.907-11.

6 Murdock, G.P., "The Cross-Cultural Survey", American Sociological Review 5, 3 (June 1940), 361-70, p.361.

7 Murdock, "The Cross-Cultural Survey", p.362.

8 Murdock, G.P., et.al., Outline of Cultural Materials (New Haven: Yale University Press, 1945), p.v, reprinting the foreword to the first edition of 1938.

${ }^{9}$ Murdock, G.P., et.al., Outline of Cultural Materials, 3rd revised ed.(New Haven: Human Relations Area Files, Inc., 1950), p.xii.

${ }^{10}$ Murdock, “The Cross-Cultural Survey," pp.362-3.

11 Whiting, John W.M., “George Peter Murdock (1897-1985)", American Anthropologist 88, 3 (September, 1986), 682-6, pp. 684-5; my emphasis.

12 Murdock, "The Cross-Cultural Survey," p.363.

13 Murdock, G.M., Outline of World Cultures, 3rd revised ed. (New Haven: Human Relations Area Files, Inc., 1963), pp.125-7.

14 Murdock, Cultural Materials, p.xviii.

15 See, Murdock, Cultural Materials, pp.xix-xx.
${ }^{16}$ And, indeed, to echo Borges's taxomony of animals from the "Celestial Emporium of Benevolent Knowledge" (famously cited by Michel Foucault in the preface to The Order of Things): “(a) those that belong to the Emperor, (b) embalmed ones, (c) those that are trained, (d) suckling pigs, (e) mermaids, (f) fabulous ones, (g) stray dogs, (h) those that are included in this classification, (i) those that tremble as if they were mad, (j) innumerable ones, (k) those drawn with a very fine camelhair brush, (l) others, (m) those that have just broken a flower vase, (n) those that resemble flies from a distance." (J.L. Borges, "The Analytical Language of John Wilkins", in Other Inquisitions 1937-1952, trans., Ruth L.C. Simms (Austin: University of Texas Press, 1964), p.103.)

${ }^{17}$ For a critique on these grounds, see Köbben, A.J., "New Ways of Presenting an Old Idea: The Statistical Method in Social Anthropology", in Frank W. Moore (ed.), Readings in Cross-Cultural Methodology (New Haven: HRAF Press, 1966), 166-92.

18 Stocking, G.W. Jr., Victorian Anthropology (New York: The Free Press, 1987), p.316.

19 Swanson, G.E., The Birth of the Gods: The Origin of Primitive Beliefs (Ann Arbor: The University of Michigan Press, 1966, first ed. 1961), p.1. For detailed analysis of four other studies from this school Murdock's own Social Structure (New York: Macmillan, 1949), D. Horton's “The Functions of Alcohol in Primitive Societies", Quarterly Journal of Studies in Alcohol, 4 (1943), C.S. Ford's A Comparative Study of Human Reproduction (New Haven: Yale University Press, 1945) and L.W. Simmons's The Role of the Aged in Primitive Society (New Haven: Yale University Press, 1945) - see Köbben, "New Ways of Presenting an Old Idea", pp.180-91.

20 Swanson, The Birth of the Gods, p.81. Swanson's "certain anthropologists" are Father Wilhelm Schmidt and his followers: the work Swanson refers to in particular is Schmidt's The Origin and Growth of Religion, Facts and Theories, translated by H.J. Rose (London: Methuen and Co., 1935).

${ }^{21}$ Thus, for instance, "The importance of cross-cultural comparisons in helping to clarify, sharpen, limit, and enlarge the instrumental concepts which are being used in the analysis of our own society", in Mead, M., "Public Opinion Mechanisms among Primitive Peoples", The Public Opinion Quarterly, 1, 3 (July 1937): 5-16, p.5.

22 Hurwitz, H.J., Military Government and the German Press: an Experiment in Cross-Cultural Institutional Change, Masters Thesis, Columbia University, 1954; H. A. Gould, The Japanese Student's View of America: a Study in Cross-Cultural Perception, Masters Thesis, Ohio State University, 1954. 


\section{Historicizing "Cross-Cultural"}

23 Parker, Philip, M., Cross-Cultural Statistical Encyclopedia of the World (vol.1, Religious Cultures, vol.2, Linguistic Cultures, vol.3, Ethnic Cultures, vol.4, National Cultures) (Westport: Greenwood Press, 1997), Daniela Breveníková et al. (eds.), CrossCultural and Interdisciplinary Aspects of Teaching Languages for Professional Communication (Bratislava: Ústav jazykov Ekonomickej univerzity v Bratislave, 1997), Hana S. Noor Al-Deen (ed.), Cross-Cultural Communication and Aging in the United States (Mahwah, N.J.: Erlbaum, 1997).

24 Gorlier, Claudio and Isabella Maria Zoppi (eds.), Cross-Cultural Voices: Investigations into the PostColonial (Rome: Bulzoni, 1997), p.13.

25 http://www.anu.edu.au/culture/research.php (accessed 7.4.07) 